\title{
Sistem Rekomendasi Minat Anak Menggunakan Alat Tes Rothwell Miller Interest Blank Berbasis Web
}

\author{
M. Tsana'uddin Farid \\ Departemen Teknik Elektro dan Teknologi Informasi \\ Universitas Gadjah Mada \\ tsanauddinfarid@mail.ugm.ac.id
}

\begin{abstract}
Abstrak
Indonesia Career Center Network menemukan fakta bahwa $87 \%$ mahasiswa Indonesia merasa salah jurusan. Salah jurusan merupakan salah satu faktor dalam penurunan performa belajar dan tidak sedikit pelajar yang akhirnya memutuskan untuk tidak melanjutkan studi. Kejadian ini dapat dicegah dengan mendeteksi minat anak sejak dini agar orang tua dan guru dapat mengarahkan mereka kepada kebutuhan potensi dan pendidikan mereka. Salah satu cara mendeteksi minat anak adalah berkonsultasi langsung kepada psikolog pendidikan. Minat anak dideteksi oleh psikolog melalui alat tes yang dilakukan secara manual. Kendala dari proses ini adalah waktu yang dibutuhkan tidak singkat karena memerlukan ketelitian dalam menghitung, memeriksa hasil dan memberikan rekomendasi. Kesalahan proses analisis kalkulasi dari alat tes kapanpun dapat terjadi yang berakibat kesalahan dalam mendeteksi minat seseorang. Penelitian ini membahas pengembangan sistem rekomendasi berbasis web yang bertujuan membantu pakar agar analisis minat anak menjadi lebih cepat, fleksibel dan tercegah dari kesalahan. Metode Waterfall digunakan untuk mengembangkan sistem dan alat tes RothwellMiller Interest Blank digunakan untuk perhitungan dalam mendeteksi minat anak. Sistem ini diujikan dengan 20 sampel dan semua hasil deteksi keluaran dari sistem sesuai dengan hasil deteksi dari pakar. Hasil pengujian menunjukkan bahwa sistem ini memberikan akurasi yang sangat baik sehinga dapat membantu pakar dalam mendeteksi minat anak.
\end{abstract}

Kata kunci: Sistem Rekomendasi, Web, Waterfall, Minat, Rothwell-Miller Interest Blank

\begin{abstract}
The Indonesia Career Center Network found that $87 \%$ of Indonesian students felt they were on the wrong education path. This situation is one of the factors in decreasing learning performance. These incidents can be prevented by early detection of children's interests. Children's interests could be detected by doing a consultation with an educational psychologist. A psychologist detects children's interest through manual tests. The problem with this process takes a long time because it requires accuracy in calculating, checking results, and providing recommendations. Errors in the calculation analysis process from the test tool can occur at any time, which results in errors in detecting someone's interest. This study discusses developing a web-based system that aims to assist experts in analyzing children's interests to be faster, more flexible, and error-prevented. The Waterfall method is used to develop a system, and the Rothwell-Miller Interest Blank method is used for calculations in detecting children's interests. This system was tested with 20 samples, and all the output detection results from the system were in accordance with the detection results from experts. The test results indicate that this system provides excellent accuracy to assist experts in detecting children's interests.
\end{abstract}

Keywords: Recommender System, Web, Waterfall, Interest, Rothwell-Miller Interest Blank 


\section{PENDAHULUAN}

Memilih karier adalah salah satu keputusan terpenting yang akan kita lakukan dalam hidup. Memilih karier yang tepat membutuhkan waktu dan pertimbangan yang matang. Salah satu peran penting dalam memilih karier ada dengan mengetahui minat [1]. Minat adalah peran penting untuk mengarahkan arah karir dimulai dari menentukan jalur pendidikan yang akan ditempuh [2]. Jika tidak mengetahui minat potensi dengan baik maka akan menjerumuskan anak ke penyesalan dalam pilihan mereka [3]. Sehingga, akan lebih baik apabila menentukan pilihan sesuai dengan minat kita. Hal ini dimulai sejak kita menentukan jurusan kuliah. Penelitian Indonesia Career Center Network menemukan fakta bahwa $87 \%$ mahasiswa Indonesia merasa salah jurusan. Berdasarkan hasil survey dikatahui bahwa $62.5 \%$ mahasiswa dunia mengalami putus asa dengan pendidikan yang mereka tempuh [4].

Kasus salah jurusan dapat menjadi faktor dalam penurunan performa belajar dan tidak sedikit pelajar yang akhirnya memutuskan untuk tidak melanjutkan studi [5]. Kejadian ini dapat dicegah dengan mendeteksi minat anak sejak dini agar orang tua dan guru dapat mengarahkan mereka kepada kebutuhan potensi dan pendidikan mereka. Salah satu cara mendeteksi minat anak adalah berkonsultasi langsung kepada pakar psikolog pendidikan.

Minat anak dideteksi oleh pakar melalui alat tes yang dilakukan secara manual. Kendala dari proses ini adalah waktu yang dibutuhkan tidak singkat karena memerlukan ketelitian dalam menghitung, memeriksa hasil dan memberikan rekomendasi [6]. Kesalahan proses perhitungan dan analisis alat tes kapanpun dapat terjadi yang berakibat kesalahan dalam mendeteksi minat seseorang [7].

Pandemi yang melanda menjadi kendala tambahan bagi pakar karena tidak dapat menjalankan tes minat secara langsung. Diperlukan peran sistem deteksi berbasis web sebagai solusi dari kendala dalam analisis hasil tes minat agar konsultasi dapat dilakukan jarak jauh dan analisis deteksi minat anak menjadi lebih cepat serta tercegah dari kesalahan.

Pada penelitian ini akan membahas tentang perancangan dan implementasi sistem rekomendasi untuk mendeteksi minat dengan fokus mendeteksi minat berdasarkan perhitungan standar alat tes psikologi dan akan diujikan kepada beberapa sampel untuk mengukur akurasi ketepatan sistem secara lebih baik.

\section{Rumusan Masalah}

Rumusan masalah dalam penelitian ini adalah bagaimana merancang sebuah sistem deteksi minat yang interaktif dan mudah digunakan serta mampu menampilkan data dan informasi secara akurat.

\section{Tujuan Penelitian}

Tujuan dari penelitian ini adalah untuk melakukan pengembangan sistem berbasis web untuk mendeteksi minat anak yang bertujuan dalam membantu pakar atau psikolog pendidikan agar proses analisis minat anak menjadi lebih cepat, fleksibel dan tercegah dari kesalahan.

\section{Manfaat Penelitian}

1. Bagi lembaga diharapkan dapat dengan memudahkan proses analisis minat anak secara efisien dan membantu 
proses bisnis konsultasi karir menjadi lebih efeksi.

2. Bagi klien, keluaran dari penelitian ini dapat membantu memudahkan mereka dalam melakukan tes deteksi minat secara jarak jauh dengan psikolog pendidikan melalui web yang akan dibangun.

3. Bagi mahasiswa, penelitian ini akan menambah wawasan di luar bidang studi tentang psikologi pendidikan dan keterampilan dalam menerapkan pengetahuan tentang teknologi informasi.

\section{Tinjauan Pustaka}

Penelitian tentang sistem pendukung keputusan bidang minat menggunakan metode Simple Additive Weighting dilakukan oleh Indyastuti dkk[8]. Penentuan minat dalam sistem ini berdasarkan alat tes minat Rothwell Miller Interest Blank. Sistem ini bertujuan untuk membantu siswa dalam memilih program studi yang sesuai dengan minatnya. Kekurangan dari sistem ini adalah pemberian bobot pada masing-masing kategori minat pekerjaan tidak dijelaskan berdasarkan apa. Hal ini memicu bias sistem dalam menampilkan hasil keluaran.

Rancang bangun sistem penelusuran minat dengan tes Rothwell Miller Interest Blank berbasis web dilakukan oleh Hanifudin dkk[6]. Sistem ini di tujukan pada pengelola jasa tes psikologi dan pengguna tes psikologi demi membantu kelancaran dalam melakukan tes dan keakuratan data. Kekurangan dari penelitian ini adalah tidak adanya dokumentasi laporan hasil pengujian terhadap beberapa sampel sehingga tingkat akurasi belum dapat diukur.
Penelitian membuat sistem rekomendasi minat telah dilakukan oleh Hutomo dkk[9]. Penelitian ini bertujuan untuk mendeteksi minat anak menggunakan alat tes Rothwell Miller Interest Blank dengan penambahan metode Fuzzy Logic dalam menentukan minat anak. Kekurangan dari sistem tersebut adalah masih ditemukan ketidakcocokan hasil sistem dengan hasil deteksi minat oleh pakar.

\section{LANDASAN TEORI}

\section{Sistem Rekomendasi Berbasis Web}

Sistem rekomendasi didefinisikan sebagai cara untuk membantu dan meningkatkan proses sosial dalam menggunakan rekomendasi orang lain untuk membuat pilihan ketika tidak ada pengetahuan atau pengalaman pribadi yang memadai tentang alternatif tersebut [10]. Sistem pemberi rekomendasi bermanfaat bagi penyedia layanan dan pengguna karena akan mempermudah kedua belah pihak dalam menjalankan proses bisnis yang sedang terjadi di antara mereka. Pada penelitian ini sistem rekomendasi yang dibangun berbasis web.

Aplikasi berbasis web adalah program apa pun yang diakses melalui koneksi jaringan menggunakan Hypertext Transfer Protocol [11]. World Wide Web atau biasa disebut Web adalah adalah sistem informasi di mana dokumen dan sumber daya web lainnya diidentifikasi oleh Uniform Resource Locators, yang dapat dihubungkan oleh hypertext, dan dapat diakses melalui Internet [12].

\section{Tes Minat}

Tes Rothwell Miller Interest Blank (RMIB) merupakan salah satu tes psikologi 
yang digunakan untuk mengetahui minat terhadap berbagai pekerjaan yang disusun dalam beberapa kelompok. Setiap kelompok terdiri atas 12 jenis pekerjaan dari kategori pekerjaan yang berbeda [13]. Dalam tes ini, klien diminta untuk memilih pekerjaan mana yang ingin dia lakukan atau sukai, terlepas dari jumlah gaji ataupun biaya pendidikan. Tes ini cocok untuk anak usia remaja dan pencari kerja yang bingung untuk memilih pekerjaan yang cocok untuk mereka [14]. Awalnya, Rothwell merancang sembilan karya dalam pengujiannya, kemudian dikembangkan oleh Miller menjadi 12 pekerjaan [15]. Berikut ini adalah 12 kategori pekerjaan pada tes Rothwell Miller Interest Blank:

1. Outdoor (OUT), Pekerjaan yang berhubungan dengan kegiatan luar ruangan untuk kegiatan lapangan.

2. Mechanical (ME), Pekerjaan yang menggunakan mesin, peralatan mekanik, dan juga peralatan tambahan

3. Computational (COMP), Pekerjaan yang terkait dengan angka dan operasi penghitungan (komputasi).

4. Scientific (SCI), Pekerjaan yang berhubungan dengan analisis, investigasi, penelitian, dan segala sesuatu yang berhubungan dengan sains.

5. Personal Contact (PERS), Pekerjaan yang berhubungan dengan manusia, hubungan interpersonal, diskusi, dan hubungan dengan banyak orang.

6. Aesthetic (AESTH), Pekerjaan yang berhubungan dengan seni.

7. Literary (LIT), Pekerjaan yang berhubungan dengan buku, membaca, dan segala bentuk kegiatan sastra, seperti menulis dan kritikus buku, sebagainya.
8. Musical (MUS), Pekerjaan yang berhubungan dengan musik, mulai dari memainkan alat musik, membuat musik, dan mendengarkan musik.

9. Social Service (SOS), Pekerjaan yang berhubungan dengan kehidupan sosial, pengabdian masyarakat, membantu dan juga mendorong kehidupan sesama manusia.

10. Clerical (CLER), Pekerjaan yang berhubungan dengan tugas rutin, yang membutuhkan ketelitian, sistematis, dan juga cenderung terorganisir.

11. Practical (PRAC), Pekerjaan yang praktis, membutuhkan implementasi langsung terhadap suatu keahlian dan keterampilan.

12. Medical (MED), Pekerjaan yang berhubungan dengan perawatan, penyembuhan, dan juga perawatan medis.

Secara tradisional, tes Rothwell Miller Interest Blank berupa formulir yang berisi daftar pekerjaan yang disusun dalam 9 kelompok dengan kode huruf A sampai I dan dibedakan antara laki-laki dan perempuan. Pemeringkatan dimulai dengan nomor 1 untuk pekerjaan yang paling disukai dalam kelompok dan diakhiri dengan nomor 12 untuk pekerjaan yang paling tidak disukai.

Setelah semua kolom ranking untuk setiap pekerjaan diisi oleh responden, selanjutnya hasilnya ditransfer ke kerangka kerja yang terdapat pada bagian terakhir form tes ini. Peringkat Grup A dimasukkan dalam bingkai mengikuti aslinya. Peringkat Grup B dimulai dari kolom ME, dan seterusnya. Tambahkan nilai untuk setiap jenis pekerjaan dan letakkan di kolom terakhir. Perhitungan manual hasil tes 
Rothwell Miller Interest Blank dapat dilihat pada Gambar 1.

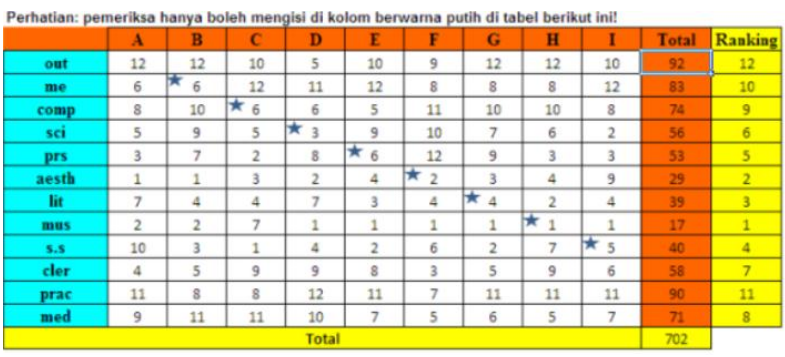

Gambar 1. Perhitungan Tes RMIB

Jika dilihat dari jumlah skornya, maka skor rendah menandakan indikasi adanya minat yang lebih besar dibandingkan dengan pekerjaan dengan skor yang lebih tinggi [15]. Sehingga, dengan melihat urutan skor pada masingmasing kategori pekerjaan, kita dapat melihat pola minat seseorang. Semakin rendah skor, pekerjaan semakin diminati dan semakin tinggi skor, pekerjaan semakin tidak diminati.

\section{METODE PENELITIAN}

\section{Metode Pengumpulan Data}

Pertama peneliti melakukan peninjauan terhadap berbagai literatur seperti buku, prosiding dan jurnal baik secara fisik maupun digital yang berkaitan dengan topik yang sedang diteliti. Selanjutnya dari tinjauan literatur, dilakukan proses identifikasi permasalahan yang timbul pada penelitian sebelumnya. Konsultasi dengan pihak yang terlibat (dalam penelitian ini adalah psikolog pendidikan) dilakukan untuk mendapatkan informasi yang dapat mendukung rencana pengembangan sistem. Proses perancangan dilakukan untuk menghasilkan sistem yang lebih relevan dan di implementasikan. Tahap akhir adalah pengujian sistem dan pembahasan hasil.

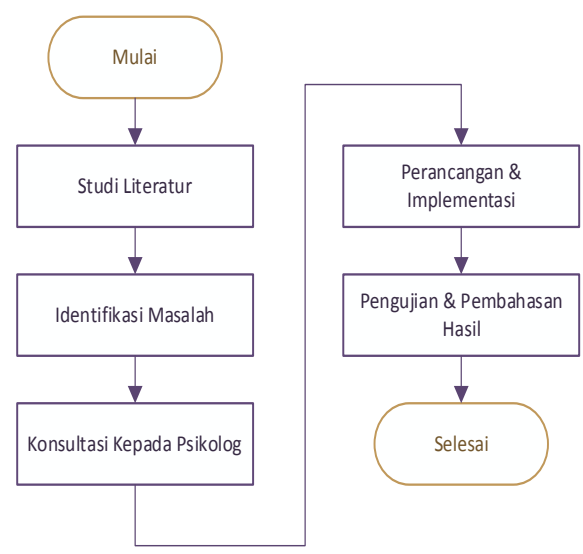

Gambar 2. Alur Penelitian

\section{Metode Pengembangan Sistem}

Metode Waterfall digunakan untuk pengembangan sistem. Model Waterfall merupakan model klasik yang digunakan dalam siklus hidup pengembangan sistem untuk membuat sistem dengan pendekatan linier dan sekuensial [16]. Metode ini disebut sebagai air terjun karena modelnya berkembang secara sistematis dari satu fase ke fase lainnya dengan cara ke bawah. Model ini dibagi menjadi beberapa fase dan keluaran dari satu fase digunakan sebagai input fase berikutnya [17]. Setiap fase harus diselesaikan sebelum fase berikutnya dimulai dan tidak ada fase yang tumpang tindih. Metode Waterfall memiliki lima fase di dalamnya, meliputi:

a. Analisis Kebutuhan, tahapan ini membutuhkan komunikasi yang kuat bertujuan untuk memahami perangkat lunak yang diharapkan oleh pengguna dan batasan sistem. Informasi ini diperoleh melalui, diskusi, wawancara atau survei langsung. Hasil analisis kebutuhan akan dapat memberikan spefikasi sistem yang akan dibuat hingga detail fungsi yang akan dihadirkan [17].

b. Desain Sistem, spesifikasi kebutuhan dari tahap sebelumnya akan dipelajari 
pada tahap ini dan perancangan sistem disiapkan. Desain sistem membantu pengembang menentukan perangkat keras dan mendefinisikan arsitektur sistem secara keseluruhan [18].

c. Implementasi, sesuai dengan namanya, pada fase ini source code ditulis sesuai kebutuhan. Spesifikasi desain fisik diubah menjadi kode kerja. Sistem dikembangkan dalam program kecil yang disebut unit, setelah itu unit-unit ini diintegrasikan.

d. Integrasi dan Pengujian, kode tersebut kemudian diserahkan kepada tim penguji. Penguji memeriksa program untuk semua kemungkinan cacat, dengan menjalankan kasus uji baik secara manual atau dengan otomatisasi. Klien akan dilibatkan dalam tahap pengujian, agar memastikan fungsionalitas sistem berjalan sesuai yang diharapkan [19]. Semua kecacatan dan bug yang terdeteksi selama tahap ini diperbaiki untuk memastikan jaminan kualitas sistem.

e. Operasi dan Pemeliharaan, tahap terakhir dalam metode Waterfall. Aplikasi sudah dijalankan oleh enduser (pengguna akhir). Perangkat lunak yang sudah selesai dijalankan dan dipelihara. Pemeliharaan termasuk memperbaiki kesalahan yang tidak ditemukan pada langkah sebelumnya [16].

\section{ANALISIS DAN PERANCANGAN Activity Diagram}

Activity Diagram atau diagram aktivitas secara visual menyajikan serangkaian tindakan atau aliran kontrol dalam sistem yang mirip dengan diagram alur atau diagram aliran data [20]. Diagram aktivitas sering digunakan dalam pemodelan proses bisnis. Diagram aktivitas sistem rekomendasi karir berdasarkan minat dalam di lihat pada Gambar 3.

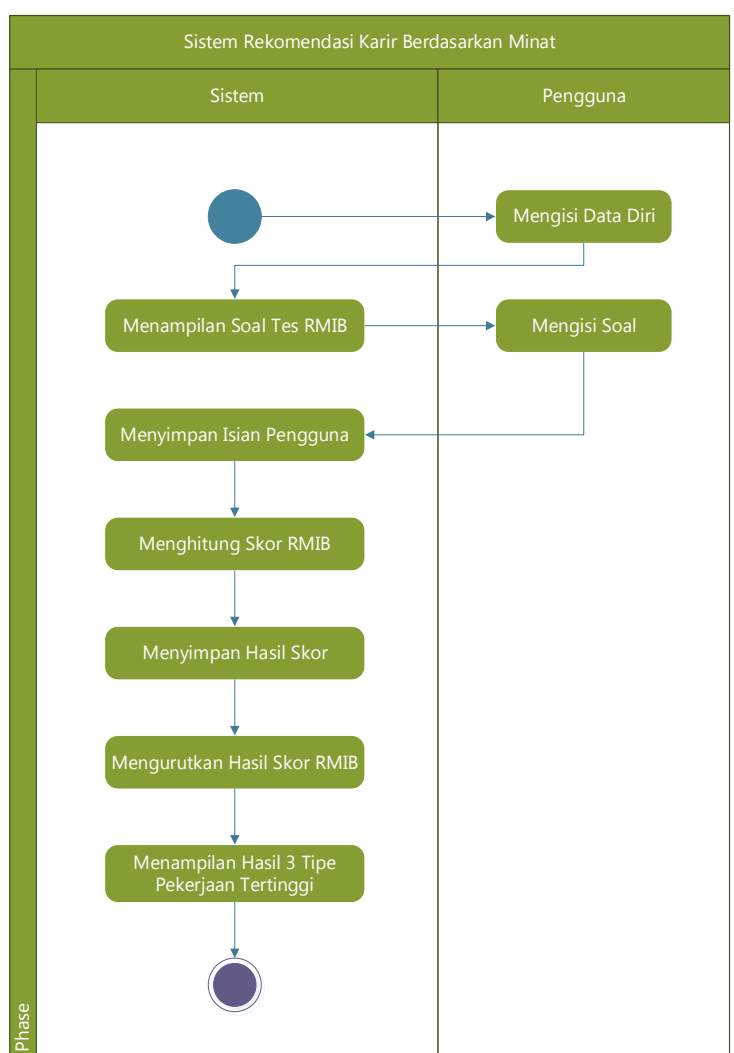

Gambar 3. Diagram Aktivitas

\section{Use Case Diagram}

Use case diagram memodelkan fungsionalitas sistem dengan menggunakan Aktor dan Use Case. Use Case adalah sekumpulan tindakan, layanan, dan fungsi yang perlu dilakukan sistem [21]. Dalam konteks ini, "Sistem" adalah sesuatu yang sedang dikembangkan atau dioperasikan, seperti situs web. "Aktor" adalah orang atau entitas yang beroperasi di bawah peran yang ditentukan dalam sistem [22]. Use Case Diagram sistem rekomendasi minat anak menggunakan alat tes Rothwell Miller Interest Blank berbasis web dapat di lihat pada Gambar 4. 


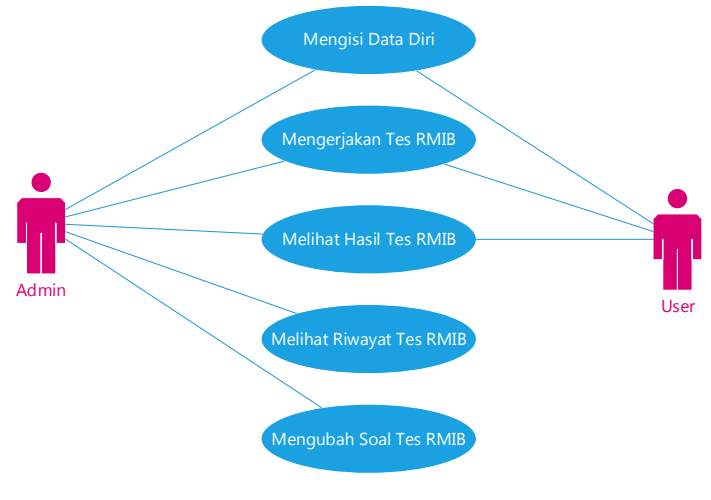

Gambar 4. Use Case Diagram

Terdapat dua orang aktor pada sistem ini, yaitu admin dan user. Admin adalah pakar atau psikolog pendidikan yang menggunakan sistem ini. Admin memiliki peran untuk mengelola data user, mengatur soal hingga mengelola hasil keluaran sistem terhadap minat seorang user. User adalah klien dari seorang psikolog yang melaksanakan tes Rothwell Miller Interest Blank pada sistem ini. Tugas utama user adalah mengisikan prioritas pekerjaan pada setiap kelompok pekerjaan agar isian tersebut dapat digunakan sistem untuk mendeteksi minatnya.

\section{IMPLEMENTASI DAN PEMBAHASAN Implementasi Sistem}

Implementasi sistem dilakukan kepada Biro Psikolog Rumah Pelangi Yogyakarta. Sistem ini dikembangkan berbasis web dengan alasan agar sistem ini dapat membantu proses konsultasi karir anak secara jarak jauh atau daring. Terdapat beberapa halaman yang menjadi bagian utama dari sistem pendukung keputusan karir ini diataranya adalah halaman pengisian tes dan halaman keluaran hasil.

Halaman pengisian tes dibuat sederhana dengan menampilkan kelompok soal menjadi 2 kolom untuk menghindari panjangnya gulir halaman. Hal ini membantu memberikan kesan bahwa sesi kelompok soal yang harus dikerjakan menjadi lebih sedikit [23]. Halaman keluaran hasil juga dibuat sederhana dengan menampilkan urutan soalnya dengan minat paling tinggi dalam tampilan putih minimalis agar memudahkan pakar melihat hasilnya secara langsung tanpa distraksi ornamen di sekitarnya [24]. Tampilan antarmuka sistem rekomendasi minat anak menggunakan alat tes Rothwell Miller Interest Blank berbasis web dapat di lihat pada Gambar 5 dan Gambar 6.

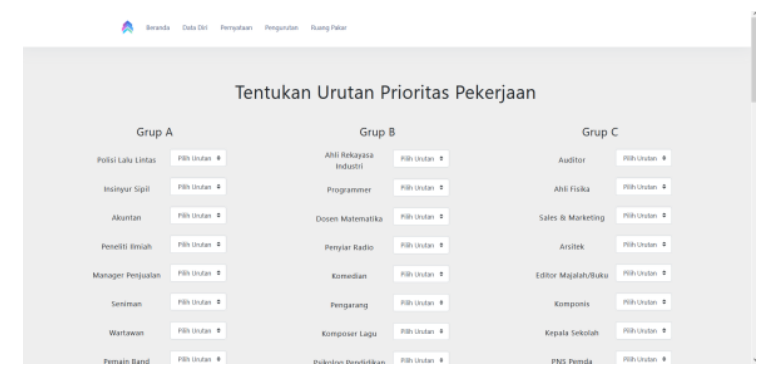

Gambar 5. Halaman Soal RMIB

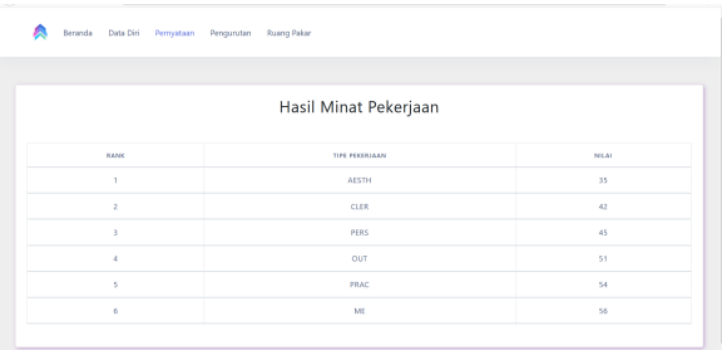

Gambar 6. Halaman Hasil RMIB

\section{Pengujian Sistem}

Pengujian sistem ini dilakukan secara langsung data klien dari Biro Psikologi Rumah Pelangi Yogyakarta. Pada saat pengujian sistem, peneliti telah mendapatkan data hasil isian yang dilakukan oleh klien dan perolehan hasil rekomendasi minat dalam bentuk kategori pekerjaan yang telah dianalisis oleh psikolog. Terdapat 20 data yang digunakan dalam pengujian ini. Data hasil keluaran sistem (yang berupa kategori minat 
pekerjaan) kemudian dibandingkan dengan hasil yang diperoleh oleh psikolog.

Nama klien disamarkan pada publikasi ini untuk menjaga kode etik dan privasi. Hasil pengujian sistem rekomendasi minat anak menggunakan alat tes Rothwell Miller Interest Blank berbasis web dapat di lihat pada Tabel 1.

Tabel 1. Hasil Pengujian Akurasi

\begin{tabular}{|c|c|c|c|c|}
\hline No & $\begin{array}{l}\text { Nama } \\
\text { Klien }\end{array}$ & Keluaran Sistem & Keluaran Pakar & Kesesuaian \\
\hline 1 & $\begin{array}{c}\text { Data } \\
1\end{array}$ & $\begin{array}{l}\text { MUS, AESTH, ME, } \\
\text { PRAC }\end{array}$ & $\begin{array}{l}\text { MUS, AESTH, } \\
\text { PRAC }\end{array}$ & Sesuai \\
\hline 2 & $\begin{array}{l}\text { Data } \\
2\end{array}$ & $\mathrm{MED}, \mathrm{ME}, \mathrm{SCI}$ & $\mathrm{MED}, \mathrm{ME}, \mathrm{SCI}$ & Sesuai \\
\hline 3 & $\begin{array}{c}\text { Data } \\
3\end{array}$ & AESTH, OUT, PERS & AESTH, OUT, PERS & Sesuai \\
\hline 4 & $\begin{array}{c}\text { Data } \\
4\end{array}$ & SS, CLER, COMP & SS, CLER, COMP & Sesuai \\
\hline 5 & $\begin{array}{c}\text { Data } \\
5\end{array}$ & MED, ME, MUS & MED, ME, MUS & Sesuai \\
\hline 6 & $\begin{array}{l}\text { Data } \\
6\end{array}$ & PERS,AESTH,COMP & PERS,AESTH,COMP & Sesuai \\
\hline 7 & $\begin{array}{c}\text { Data } \\
7\end{array}$ & MED, SCI, ME & MED, SCI, ME & Sesuai \\
\hline 8 & $\begin{array}{l}\text { Data } \\
8\end{array}$ & MED, AESTH, MUS & MED, AESTH, MUS & Sesuai \\
\hline 9 & $\begin{array}{c}\text { Data } \\
9\end{array}$ & SCI, LIT, AESTH & SCI, LIT, AESTH & Sesuai \\
\hline 10 & $\begin{array}{c}\text { Data } \\
10\end{array}$ & PERS, AESTH, ME & PERS, AESTH, ME & Sesuai \\
\hline 11 & $\begin{array}{c}\text { Data } \\
11\end{array}$ & LIT, AESTH, MUS & LIT, AESTH, MUS & Sesuai \\
\hline 12 & $\begin{array}{l}\text { Data } \\
12\end{array}$ & AESTH, ME, LIT & AESTH, ME, LIT & Sesuai \\
\hline 13 & $\begin{array}{c}\text { Data } \\
13\end{array}$ & CLER, MED, COMP & CLER, MED, COMP & Sesuai \\
\hline 14 & $\begin{array}{c}\text { Data } \\
14\end{array}$ & OUT, AESTH, PERS & OUT, AESTH, PERS & Sesuai \\
\hline 15 & $\begin{array}{l}\text { Data } \\
15\end{array}$ & $\begin{array}{l}\text { MUS, PRAC, PERS, } \\
\text { MED }\end{array}$ & MUS, PRAC, MED & Sesuai \\
\hline 16 & $\begin{array}{c}\text { Data } \\
16\end{array}$ & $\begin{array}{c}\text { AESTH, CLER, } \\
\text { PERS }\end{array}$ & $\begin{array}{c}\text { AESTH, CLER, } \\
\text { PERS }\end{array}$ & Sesuai \\
\hline 17 & $\begin{array}{c}\text { Data } \\
17\end{array}$ & $\begin{array}{l}\text { AESTH, PRAC, } \\
\text { COMP }\end{array}$ & $\begin{array}{l}\text { AESTH, PRAC, } \\
\text { COMP }\end{array}$ & Sesuai \\
\hline 18 & $\begin{array}{c}\text { Data } \\
18\end{array}$ & MUS, AESTH, LIT & MUS, AESTH, LIT & Sesuai \\
\hline 19 & $\begin{array}{c}\text { Data } \\
19\end{array}$ & $\begin{array}{l}\text { AESTH, OUT, } \\
\text { PRAC,ME }\end{array}$ & $\begin{array}{l}\text { AESTH, OUT, } \\
\text { PRAC,ME }\end{array}$ & Sesuai \\
\hline 20 & $\begin{array}{c}\text { Data } \\
20\end{array}$ & MUS, LIT, COMP & MUS, LIT, COMP & Sesuai \\
\hline
\end{tabular}

Berdasarkan Tabel 1, 20 sampel telah diuji pada sistem rekomendasi berbasis web. Hasil pengujian menunjukan bahwa sistem ini berhasil menampilkan keluaran yang sesuai dengan analisis rekomendasi minat dari psikolog. Setiap rekomendasi psikolog menampilkan 3 urutan minat tertinggi, begitu pula sistem rekomendasi. Namun, sistem rekomendasi juga akan mendefinisikan 4 urutan minat tertinggi apabila ditemukan kesamaan total nilai total dalam kategori pekerjaan.

\section{KESIMPULAN}

Berdasarkan hasil dari implementasi dan pengujian dari sistem pendukung keputusan dapat disimpulkan secara kesuluruhan bahwa sistem ini telah berjalan dengan baik sesuai dengan yang diharapkan oleh pengembang maupun pengguna. Kehadiran sistem ini telah mampu mengatasi masalah konsumsi waktu yang dialami oleh pakar atau praktisi dalam mendeteksi minat seseorang. Automasi perhitungan sistem ini telah mampu menghindari kemungkinan kesalahan pakar dalam melakukan perhitungan hasil tes Rothwell Miller Interest Blank.

Pengembangan sistem ini yang berbasis web telah mampu membantu proses konsultasi karir antara pakar dan klien secara jarak jauh. Tingkat persentasi kesesuaian hasil deteksi pakar dan sistem menandakan bahwa sistem ini akurat, terpercaya dan dapat diandalkan

\section{Saran}

Adapun saran penelitian ini untuk penelitian selanjutnya adalah:

1. Perlu adanya identifikasi nilai rata-rata dari setiap isian prioritas pekerjaan agar dapat mengatasi pengurutan rekomendasi minat yang memiliki kesamaan skor total.

2. Perlu pengembangan terhadap keamanan website untuk menjaga keamanan dan privasi data.

\section{DAFTAR PUSTAKA}

[1] J. G. Maree, "Promoting career development in the early years of a person's life through self-and career construction counseling (using an integrated, qualitative + quantitative approach): a case study," Early Child Development 
and Care 188, no. 4 (2018), ISSN: 1476-8275.

[2] A. Afzal Humayon, S. Raza, R. Aamir Khan, and N. ul ain Ansari, "Effect of Family Influence, Personal Interest and Economic Considerations on Career Choice amongst Undergraduate Students in Higher Educational Institutions of Vehari, Pakistan," International Journal of Organizational Leadership 7, no. 2 (2018), ISSN: 2345-6744.

[3] Y. M. Jung, "Nursing students' career identity, satisfaction with major, and career stress by career decision type," Japan Journal of Nursing Science 17, no. 1 (2020), ISSN: 17427924.

[4] A. S. Imamul, W. Primayasa, and M. Y. Baharsyah, "Pengaruh Salah Pilih Jurusan Terhadap Rasa Putus Asa Mahasiswa Teknik Informatika," Nathiqiyyah 3, no. 1 (2020).

[5] J. S. Plasman and M. A. Gottfried, "Applied STEM Coursework, High School Dropout Rates, and Students With Learning Disabilities," Educational Policy 32, no. 5 (2018), ISSN: 0895-9048.

[6] M. Hanifudin, "Sistem Penunjang Keputusan Pemilihan Jurusan Perguruan Tinggi Menggunakan Teori Psikologi Rothwell Miller Interest Blank (RMIB) Muhammad," J-INTECH 6, no. 01 (2018), ISSN : 1098-6596.

[7] R. Goddard, R. Simons, W. Patton, and K. Sullivan, "Psychologist handscoring error rates on the Rothwell Miller Interest Blank: A comparison of three job allocation systems," Australian Journal of Psychology 56, no. 1 (2004), ISSN: 00049530.

[8] D. Indyastuti, J. D. Irawan, and R. P. Prasetya, "Sistem Pendukung Keputusan Bidang Minat Menggunakan Metode Simple
Additive Weighting," JATI (Jurnal Mahasiswa Teknik Informatika) 4, no. 1 (2020), ISSN : 2302-2426.

[9] A. T. Hutomo, M. Nasrun, and C. Setianingsih, "Web-Based Psychological Rothwell Miller Interest Blank (RMIB) Test using Fuzzy Method," IEEE International Conference on Industry 4.0, Artificial Intelligence, and Communications Technology (IAICT) 2020, ISBN: 9781728193366.

[10] F. O. Isinkaye, Y. O. Folajimi, and B. A. Ojokoh, "Recommendation systems: Principles, methods, and evaluation," Egyptian Informatics Journal 16, no. 3 (2015), ISSN: 11108665.

[11] A. Yanie et al., "Web-Based Application for Decision Support System with ELECTRE Method," Journal of Physics: Conference Series, vol. 1028, no. 1 (2018), ISSN: 17426596.

[12] J. Vass, J. Harwell, H. Bharadwaj, and A. Joshi, "World Wide Web," IEEE Potentials 17, no. 4 (1998), ISSN: 02786648.

[13] Mudhar, "Perbedaan Minat Karir Antara Siswa Sekolah Menengah Pertama (SMP) Dengan Siwa Madrasah Tsanawiyah (MTs)," HELPER: Jurnal Bimbingan dan Konseling 32, no. 2 (2016), ISSN : 0216-2938.

[14] A. Handayani, J. Kuncoro, and ..., "Penelusuran Minat Karir Millennial," PLAKAT (Pelayanan Kepada Masyarakat) 1, no. 2 (2019), ISSN : 2714-5239.

[15] S. A. Carless and B. Fallon, "The Relationship between RothwellMiller Interest Categories and Abilities," Australian Journal of Career Development 11, no. 1 (2002), ISSN: 1038-4162.

[16] D. Hughey, "The Traditional Waterfall Approach," University of 
Missouri (2017), ISSN: 0076-9703.

[17] K. Chari and M. Agrawal, "Impact of incorrect and new requirements on waterfall software project outcomes," Empirical Software Engineering 23, no. 1 (2018), ISSN: 15737616.

[18] C. J. Wells, "Systems Analysis and Design - The Waterfall Model," Technology UK (2014). ISSN: 2049-3444.

[19] G. Fraser and J. M. Rojas, "Software Testing," in Handbook of Software Engineering (2019), ISSN: 18826652.

[20] R. Fauzan, D. Siahaan, S. Rochimah, and E. Triandini, "Activity Diagram Similarity Measurement: A Different Approach," International Seminar on Research of Information Technology and Intelligent Systems (2018), ISBN: 9781538674222.

[21] T. A. Kurniawan, "Pemodelan Use Case (UML): Evaluasi Terhadap beberapa Kesalahan dalam Praktik," J. Teknol. Inf. dan Ilmu Komput 5, no. 1 (2018), ISSN : 2355-7699.

[22] S. Sabharwal, P. Kaur, and R. Sibal, "Empirical and Theoretical Validation of a Use Case Diagram Complexity Metric," International Journal of Information Technology and Computer Science 9 no. 11, 2017, ISSN: 20749007.

[23] E. C. Hallett, W. Dick, T. Jewett, and K. P. L. Vu, "How screen magnification with and without Word-Wrapping affects the user experience of adults with low vision," International Conference on Applied Human Factors and Ergonomics (2018), ISSN: 21945357.

[24] Y. C. Liu and C. H. Ko, "The effects of website white space on university students," International Conference of Design, User Experience, and Usability (2017), ISSN: 16113349. 